Philipp Weisser*

\title{
Implicational Complement Coordination and beyond: Towards a coherent theory of asymmetric coordination in German
}

https://doi.org/10.1515/zfs-2019-0003

\begin{abstract}
A certain class of predicates in German optionally allows for their complement clause to appear as coordinated with the matrix clause rather than embedded into it. This construction, which I will call Implicational Complement Coordination, exhibits all the hallmark properties of Asymmetric Coordination: Despite technically being in a conjunct position, the clause in question behaves like a subordinate clause with respect to asymmetric binding, asymmetric scope of negation and adverbs as well as asymmetric extraction. Based on the detailed description of the phenomenon by Reis (1993), it can be shown that this coordinate construction mimics its infinitival counterpart with respect to these syntactic tests. In this paper, I argue that this can be accounted for by saying that the coordinate construction is derived on the basis of its subordinate counterpart by means of movement. The subordinate properties of the second conjunct then derive from its derivational history as a subordinate clause. Further, I will show that even though other cases of Asymmetric Coordination (in German) lack a minimally different infinitival counterpart, they can and should still be derived from an underlyingly subordinate syntax.
\end{abstract}

Keywords: asymmetric coordination, coordination, infinitives, binding, movement

\section{Introduction}

Even though cases of asymmetric coordination are often seen as somewhat marginal constructions, they arguably concern the heart of matters of generative theorizing. This is because they cast doubt on virtually all the otherwise robust diagnostics of syntactic hierarchy: Binding of anaphors and variables, semantic scope, extraction, etc. In the case of asymmetric coordination constructions, all these diagnostics suggest that the relation between the two clauses is in

*Corresponding author: Philipp Weisser, Institut für Linguistik, Universität Leipzig, Leipzig, Germany, e-mail: philipp.weisser@uni-leipzig.de 
fact subordinate even though it looks like a regular coordination construction on the surface.

Over the course of the past fifty years, the relevant literature has found and documented a wide range of these constructions. Beginning with Ross (1967), it has been noted several times that all of these constructions seem to violate the hallmark properties of clausal coordination in one way or the other. (1) illustrates some examples of asymmetric coordination:

(1) a. This is the whiskey, he went to the store and bought.

(Ross 1967: 168)

b. This is the stuff, the guys in the caucasus drink and live to be a hundred. (Lakoff 1986: 156)

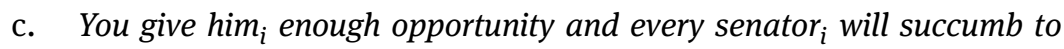
corruption.

(Culicover and Jackendoff 1997: 204)

This phenomenon is, of course, not restricted to English. Other Germanic languages seem to have constructions with the same or very similar properties. Here are some examples from German:

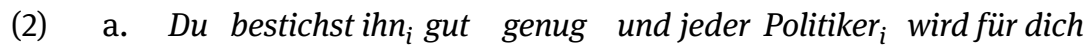
You bribe him good enough and every politician will for you abstimmen.

vote

'You bribe him sufficiently and every politician will vote for you.'

b. Seine Bücher verkaufte er und wandte sich der Malerei zu His books sold he and turned SELF the painting to 'He sold his books and turned to the art of painting.'

(Höhle 1990: 234)

In all of these examples, we find that even though the structure looks like a simple coordinate one, the underlying semantics does not. Often, it seems that these constructions convey a meaning that resembles the meaning of a subordinate construction rather than a coordinate one. One of the conjuncts is interpreted as backgrounded and the other one as foregrounded.

And, along with this asymmetry in the semantics of these constructions, we find asymmetric behavior with respect to many syntactic tests. Many of these constructions above allow for asymmetric extraction out of only one of the conjuncts - something which is normally excluded by the Coordinate Structure Constraint (Ross 1967). Also, we often find cases of binding of an element in one conjunct by an element deeply embedded in the other conjunct. Since binding is usually 
assumed to be possible only under c-command, this is completely unexpected in a coordination of two clauses. Finally, in many cases, we find that some elements (adverbs, negation, etc.) in one conjunct can take scope over the other conjunct as well. Again, this is completely unexpected. And since tests like binding, scope or extraction are usually thought of as the strongest diagnostics of syntactic hierarchy and dependency we have, asymmetric coordination constructions pose a serious problem for the whole framework as such.

In this paper, I intend to make a step forward to solving this problem, based on an investigation of a special instance of asymmetric coordination in German, namely the Implicational Complement Coordination (see Reis 1993) and its subordinate counterpart, the Implicational Complement Infinitive. I will show that these two constructions behave absolutely parallel with respect to the decisive diagnostics such as binding, extraction and semantic scope. I will take this as a basis to propose a derivation where the former construction is derived on the basis of the latter. I will show that subordinate and coordinate structures do not necessarily exclude each other. Rather, it is possible to derive one structure on the basis of the other by means of simple, regular operations we employ in the grammar anyway. In doing so, I provide for a straightforward solution for the unexpected behavior of the diagnostics above.

The paper is structured as follows: In Section 2, I will discuss the Implicational Complement Coordination, its syntactic properties and compare them to the minimally different infinitival construction. In Section 3, I will discuss the findings of Section 2 in the light of the broader picture of asymmetric coordination in general. In Section 3, I will provide an analysis of the Implicational Complement Coordination and show how it can account for the seemingly contradictory properties of the construction. In Section 4, I will then turn to another case of asymmetric coordination from German, SLF-coordination. ${ }^{1}$ I will show that even though SLF-coordination does not have an immediate subordinate counterpart, the basic properties of the construction can be derived easily if we assume that SLF-coordination is nevertheless derived on the basis of a subordinate structure. Section 5 discusses some remaining issues and compares the two constructions from a more abstract perspective. Section 6 concludes.

\section{Implicational Complement Coordination}

In this section, we will take a closer look at a special kind of asymmetric coordination constructions, the Implicational Complement Coordination (ICC). In par-

1 The abbreviation SLF stands for Subjektlücke in finiten Sätzen 'subject gap in finite clauses'. 
ticular, we will see that it patterns absolutely parallel with its infinitival counterpart, the so-called Implicational Complement Infinitive (ICI). This will provide the foundation for my argument that the former is in fact derived on the basis of the latter.

ICCs consist of two clauses coordinated by the conjunction und 'and'. The interesting characteristic of this construction is that the relation that holds between the two clauses is usually taken to be predicate-argument relation. In other words, the second clause is understood as the semantic complement of the first one. The ICC in (3-a) alternates with an infinitive construction, which I will call Implicational Complement Infinitive (ICI) (3-b) and which is semantically equivalent.

a. Hans war so nett und besuchte sie. Hans was so nice and visited her

b. Hans war so nett, sie zu besuchen. Hans was so nice her to visit 'Hans was nice enough to visit her.' (Reis 1993: 204)

ICIs and ICCs in German are possible with quite a number of predicates, many of which are evaluative adjectives such as nett 'nice', gut 'gut', blöd 'stupid', etc. In addition, there is a class of verbs allowing for both constructions such as wagen 'to dare' and sich aufraffen 'to pull oneself together' and finally there is a number of light verb constructions such as den Gefallen tun 'to do the favor', eine Freude machen 'give s.o. a treat', etc. ${ }^{2}$ (4) and (5) give two more examples with non-adjectival predicates:

(4) a. Ich bin froh, dass Hans sich endlich aufrafft und sich einen Job Ich am happy that Hans self finally pull.together and self a job sucht. seeks.

b. Ich bin froh, dass Hans sich endlich aufrafft, sich einen Job zu I am happy that Hans self finally pull.together self a job to suchen. seek. 'I am happy that Hans finally pulls himself together in order to look for a job.'

2 See Reis (1993) for a complete list of possible predicates. Also see Reis (1993) for an elaborate discussion about whether these predicates can be defined semantically. 
(5) a. Mach' ihr doch eine Freude und komm' zu ihrer Party. Make her PRT a delight and come to her party

b. Mach' ihr doch die Freude, zu ihrer Party zu kommen. Make her PRT the delight to her party to come 'Make her happy by going to her party.'

(4) and (5) further illustrate that these constructions can occur in different clausal environments such as verb-final subordinate clauses and verb-initial imperative clauses.

More of the syntactic properties of the construction will be presented in the course of the discussion. We will start with the subordinate properties of the construction which constitute the major puzzle from a syntactic point of view.

\subsection{The subordinate properties of the ICC}

The main challenge that I will try and overcome in this paper is that these two constructions pattern alike with respect to many diagnostics we have to identify syntactic hierarchy/dependency.

First, we test for extraction. Extraction is known to be bad out of a single conjunct of a coordination. This is excluded by the Coordinate Structure Constraint. However, of course, the Coordinate Structure Constraint does not affect subordinate constructions, which should thus be transparent for extraction. As we see in (6), extraction from the subordinate construction, the ICI, is possible. (6-a) illustrates examples with extraction from the matrix clause while in (6-b), we see asymmetric extraction from the infinitival clause.
a. $[\mathrm{Zu} \text { wem }]_{i}$ war Peter so $t_{i}$ nett, die Blumen zu gießen?
To whom was Peter so nice the flowers to water
b. $\quad[\text { Für wen }]_{i}$ war Peter so nett, die Blumen $t_{i}$ zu gießen?
To whom was Peter so nice the flowers to water

However, unexpectedly, the extraction patterns are identical with the coordinate counterpart, the ICC. In (7), we see two examples from extraction out of the first conjunct, and in (8), we see examples of extraction out of the second conjunct: ${ }^{3}$

3 It should be acknowledged that not all speakers find extraction equally good. Especially extraction out of the second conjunct seems to be somewhat marked for some speakers. The judgments reported in this section are based on Reis (1993) and a relatively small number of German native speakers I consulted. I briefly discuss possible sources of this variation in footnote 21 in Section 3.3. 
(7) a. Ich frage mich, wem Peter $_{i}$ den Gefallen tat und abhaute.

I ask myself whom Peter the favor did and left.

b. $[\mathrm{Zu} \text { wem }]_{i}$ war Peter so $t_{i}$ nett und goss die Blumen?

To whom was Peter so nice and watered the flowers

(8) a. [Für wen $]_{i}$ war Peter so nett und goss die Blumen $t_{i}$ ?

For whom was Peter so nice and watered the flowers

b. Ich frage mich, [zu welchem Treffen $]_{i}$ Peter uns den Gefallen tut

I ask myself to which meeting Peter us the favor does

und $t_{i}$ kommt?

and comes

Second, the both constructions pattern alike with respect to syntactic binding. With regular coordinate constructions, it is impossible to have an anaphor or a variable in one conjunct that is bound by an element in another conjunct. Consider the following example: ${ }^{4}$

(9) *Tina backte jedem bu Weihnachten einen Kuchen und hilft seiner $_{i}$

She baked everyone for christmas a cake and helps his

Mutter bei der Steuererklärung.

mother with the tax.declaration.

Consider now the same construction with the ICC. In (10-a), in the infinitive construction, binding of the variable is expected since we assume there to be syntactic c-command. However, in (10-b), which is the ICC, binding of the variable is similarly possible.

(10) a. Sie tat jedem jen Gefallen, seiner $_{i}$ Mutter eine E-mail zu She did everyone the favor his mother an email to schicken.

send

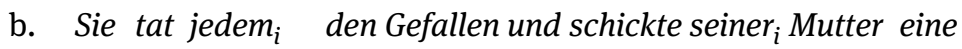
She did everyone the favor and send his mother an E-mail. email

4 The following example contains a tense mismatch in both conjuncts in order to exclude a fused interpretation. Otherwise the example can potentially receive a derivation of an SLF-construction which makes binding possible. (See Barnickel (2017) for discussion and more arguments that seemingly symmetric examples can potentially also receive an SLF-interpretation). 
The third and final diagnostic I want to look at is the scope of adverbs and negation. In (11), which is a case of regular symmetric coordination, we see that the negation in the first conjunct does not take scope over the second conjunct. The second conjunct is not interpreted as negated.

Es ist schade, dass sie nicht kommt und lieber ins Kino geht.

It is bad that she not comes and rather into.the cinema goes.

Compare, however, the following examples. In (12-a), which is quite parallel to (11), the negation takes scope over the second conjunct. The second conjunct is interpreted as negated. This, again, patterns with the corresponding examples in the infinitival construction (12-b).

a. Es ist schade, dass sie nicht so nett war und ihm einen Kuchen

It is bad that she not so nice was and him a cake

backte.

baked.

b. Es ist schade, dass sie nicht so nett war, ihm einen Kuchen zu

It is bad that she not so nice was him a cake to

backen.

bake

a. Er ist leider nicht so nett, ihr einen Kuchen zu backen.

He is unfortunately not so nice her a cake to bake

b. Er ist leider nicht so nett und backt ihr einen Kuchen.

He is unfortunately not so nice and bakes her a cake

Similarly for high adverbs as wahrscheinlich 'probably'. In both the coordinate construction in (14-a), as well as in the infinitival construction in (14-b), the adverb takes scope over the second conjunct.
a. Sie ist wahrscheinlich so nett und backt ihm einen Kuchen She is probably so nice and bakes him a cake.
b. Sie ist wahrscheinlich so nett, ihm einen Kuchen zu backen. She is probably so nice him a cake to bake

The obligatoriness of wide scope of negation and high adverbs suggests that we are dealing with a subordinate structure and not with a coordinate one. It has been noted that V2-clause coordination can enable occasional wide scope readings of negation if forced by the context (see e. g. discussion in Repp 2009) but in ICCs, crucially, the wide scope reading is obligatory in the same way that it is obliga- 
tory in the ICI. I therefore conclude that these facts are strongly suggestive of a subordinate syntax.

\subsection{The ICC in the context of asymmetric coordination in general}

In the preceding section, we have seen that the ICC, a construction that looks like a coordinate construction on the surface, patterns with its infinitival counterpart, the ICI with respect to a number of crucial properties: extraction, binding and the semantic scope of negation and high adverbs. This leaves us with a mismatch. A priori, this mismatch can be solved in two different ways:

Possibility one is to say that this only shows us that the syntactic tests we believed to be reliable are not reliable at all. Binding, extraction and the scope of adverbs and negation have nothing to do with syntactic structure at all. Rather, all of these things are computed on the basis of a different structure that is, a priori, unrelated to the morphosyntactic structure we observe. This is the road taken in Culicover and Jackendoff (1997). They argue for the conditional conjunction construction, which exhibits very similar behavior, that the only possible conclusion from this behavior is that the tests we applied are inconclusive. According to their theory, the tests merely tell us something about the semantics of the clause, not about the syntax. Further they argue, significantly departing from the standard Chomskyan architecture of grammar, that the syntax and the semantics are related only very indirectly. Two clauses can be semantically subordinate but syntactically coordinate.

The second possibility to solve this dilemma is to say that even though constructions of this sort seem to look like they were coordinate, they are actually subordinate. This is the strategy pursued in Büring and Hartmann (1998) for examples of the German SLF-coordination type. As we will see in Section 4, cases of SLF-constructions and ICCs share quite a number of syntactic properties including the asymmetries in binding, scope of negation, etc. Therefore, we could potentially entertain an analysis of ICCs along the lines of what Büring and Hartmann (1998) stated for SLF-coordination. Building on the many asymmetries we saw in the previous section, such an approach would claim that the relation between the two clauses in asymmetric coordination contexts is in fact not coordinate at all. Rather, the second conjunct appears to be adjoined to the first one. Such an analysis straightforwardly explains the unexpected behavior of the tests discussed in the preceding section. However, it does so at a high cost. Büring and Hartmann (1998) offer no explanation for why the morphosyntactic appearance of SLF-adjuncts is so different from the regular adjuncts. Regular adjuncts are of 
course never introduced by the word und and usually do not have the verb move to $\mathrm{C}$ (i. e. adjunct clauses in German are never V1- or V2-clauses). ${ }^{5}$ Furthermore, it must be noted that, even though many of the diagnostics point towards a subordinate structure, there are still some diagnostics for coordinate structures which seem to point into the other direction. Building on Reis (1993), I give two arguments that suggest that the ICC is also coordinate to a certain extent.

First, we can observe that the second conjunct in an ICC has several subordinative properties, it still cannot be moved to the prefield or even be centerembedded into the first conjunct. If this construction were true adjunction, then we would expect that it could. Consider (15) for example:

a. ${ }^{\star}$ Den Gefallen und goss die Blumen tat Hans ihr gern.

The favor and watered the flowers did Hans her with.pleasure

b. Den Gefallen, die Blumen zu gießen, tat Hans ihr gern.

The favor the flowers to water did Hans her with.pleasure

'The favor of watering the flowers, Hans did her with great pleasure.' (Reis 1993: 215)

With the infinitival construction, it is perfectly acceptable to topicalize the object that the subordinate clause is dependent on. But with the coordinate construction, it is not. Suddenly, the second conjunct no longer behaves like a subordinate clause. Similarly with Across-The-Board (ATB) movement, a process that applies only in coordinate contexts:

Wem $_{i}$ hat er $t_{i}$ einen Gefallen getan und $t_{i}$ Blumen geschenkt?

Whom has he a favor done and flowers given

ATB-movement is possible with ICCs. This would be totally unexpected under the assumption that we are dealing with a subordinate structure. ${ }^{6}$

Gapping is possible with ICCs. This would be totally unexpected under the assumption that we are dealing with a subordinate structure.

5 Of course, there are some marginal exceptions to this generalization such as the V1-conditionals as in Regnet es, bleiben wir zuhause 'If it rains, then we stay at home.' See Reis and Wöllstein (2010) for discussion of this construction. Note however, that the context of these kinds of V1-adjuncts is completely different from the second clause in asymmetric coordination constructions. V1-conditionals can, for example, only occur in the prefield in German.

6 Another process restricted to coordinate structures is Gapping and Reis (1993) gives examples which she takes as evidence that Gapping is possible in ICCs.

(i) Würdest du so nett sein und <würdest> hier mal putzen?

Would you be so nice and $<$ would $>$ here once clean

(Reis 1993: 215) 
Thus, even though an analysis along the lines of Büring and Hartmann (1998) is tempting in the face of the facts of Section 2, it still falls short of explaining the characteristics of the ICC construction. Somehow we must find a way to accommodate and derive both the subordinate properties and the coordinate properties of the construction at the same time.

\section{The analysis}

\subsection{Preliminary issues and underlying assumptions}

In this section, we will pave the way for a syntactic analysis of the construction by looking at some basic properties of the ICC construction. First, we try to identify the size of each conjunct. Since we have seen a number of examples with the verb in second position, we can tell that ICCs involve coordination of what is usually called the C'-level. Consider the following examples:

$$
\begin{aligned}
& \text { Hans }\left[{ } _ { C 1 } \text { wagt es endlich] und } \left[_{C 2}\right.\right. \text { verlässt Petra]. } \\
& \text { Hans dares it finally and leaves Petra } \\
& \text { 'Hans finally dares to leave Petra.' } \\
& { }_{C 1} \text { Sei so nett] und }\left[_{C 1}\right. \text { hau ab]! } \\
& \text { Be so nice and leave PRT } \\
& \text { 'Be so kind as to get lost.' }
\end{aligned}
$$

A standard analysis of this type of coordination would thus assume a structure along the following lines: ${ }^{7}$

\footnotetext{
But examples of this sort could also be due to conjunction of a category below the modal. Thus, it is not clear that they are necessarily instances of Gapping. And ICC examples with gapped main verbs are quite marked (see (ii) below). It is however unclear to me whether this markedness is the result of a Zeugma-effect since the verb machen is part of a collocation in the first conjunct whereas it is not in the second one.
}

(ii) ?? Er macht mir eine Freude und <macht > seine Hausaufgaben.

He does me a pleasure and $<$ does $>$ his homework

Due to these complications, I do not discuss instances of Gapping here.

7 I follow standard Minimalist assumptions that the (minimal) clausal architecture consists of the functional sequence C-T-v-V (with the slight qualification of a minimally split C - see below). I would like to emphasize though that the present analysis does not require the presence of a TPlayer (or even a vP-layer for that matter). The present paper does not provide us with arguments in the long-standing debate about the presence or absence of these projections in the German clausal spine. 
(19)

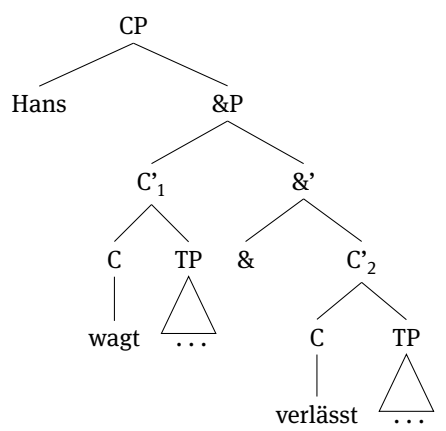

For the sake of concreteness, I will, in this paper, adopt a slightly modified version of the C-domain. In the spirit of recent proposals that assume a more fine-grained structure of the left periphery, I will assume that what is usually subsumed under the label CP is a complex phrase consisting of (at least) three different heads: FinP, Top/FocP and ForceP. FinP is the locus of finiteness and thus also the target for verb movement in V1- or V2-clauses. Top/FocP provides the prefield in its specifier and finally ForceP is the locus of clause-type related features. ${ }^{8}$

As a result, the size of each conjunct of an ICC instantiates a FinP, the only category that includes a host for verb movement but does not include a prefield position. Thus, the surface structure I will assume for a simple ICC construction looks like (20). ${ }^{9}$

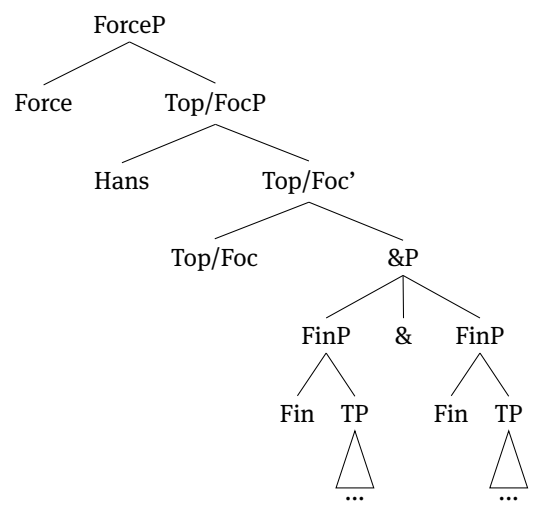

8 For discussion and complications of the Split CP-approach, see Rizzi (1997) and subsequent work. For an application of the Split CP-approach to German see Mohr (2005).

It is to be emphasized that the analysis I propose is not incompatible with the standard view of German clause structure where the prefield is located in SpecCP. To make these analyses compatible, one would simply have to assume that German has the possibility of C'-coordination (which is probably another standard assumption) and C'-adjunction.

9 Ternary \&P-structure in (20) is used for ease of exposition only. 
The next assumption that I make in the analysis in the next section concerns the identity of the subjects in both conjuncts. Both ICC and ICI constructions require the subjects of both clauses to be identical. In (21-a), the clause cannot have an implicational complement reading. Rather, the two conjuncts must be interpreted as two completely distinct events. And (21-b) is ungrammatical since it has an overt subject in an infinitive clause. ${ }^{10}$

a. \#Gestern tat ich ihr den Gefallen und er goss die Blumen. Yesterday did I her the favor and he watered the flowers

b. *Gestern tat ichihr den Gefallen, er die Blumen zu gießen. Yesterday did I her the favor he the flowers to water

The identification of the two subject positions in ICI, the infinitive construction, is unproblematic. It looks like a typical case of control into an infinitive and thus will be treated accordingly. In doing so, a construction like Er war so nett, sie zu besuchen 'He was kind enough to visit her' receives the same analysis as Er versuchte, sie zu besuchen 'He tried to visit her' in terms of subject identification. Again, for the sake of concreteness, I will adopt a standard theory of control where the subordinate clause contains an element (i. e. PRO) which is licensed by the presence of the subject in the higher clause. ${ }^{11}$

Crucially, I will assume that the identification of the two subject positions in ICC, the coordinate construction, should also be viewed as an instance of control. This, of course, raises the question how PRO can be licensed in the second conjunct of a coordination by an element that is potentially part of the first conjunct. I will answer this question in the following section.

Before we proceed, I want to point out that additional evidence for the assumption that both ICI and ICC constructions make use of control comes from Partial Control contexts, i. e. a configuration where the matrix subject is not the sole controller of what one might call PRO. Rather the matrix subject is merely a subset of the controller of PRO (22). In (23), we see that ICIs and ICCs both allow for a partial control reading.

10 Why infinitives disallow overt subjects for the most part is still subject to a bigger debate and several proposals have been made. Landau (2004) argues for example that the presence of an independent subject correlates with the presence of an independent tense feature on embedded $\mathrm{T}$. I do not want to decide here since the present account should be compatible with most explanations here.

11 The analysis at hand does not depend on the actual theory of control we adopt. If control is analyzed as Movement à la Hornstein (1999) and subsequent work, then nothing changes, at least as far as I can see at this point. 


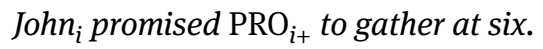
a. Hans ${ }_{i}$ ist so nett, $\mathrm{PRO}_{i+}$ sich erst um sechs zu treffen. Hans is so nice SELF only at six to meet
b. Hans ${ }_{i}$ ist so nett und $\mathrm{PRO}_{i+}$ trifft sich erst um sechs. Hans is so nice and meets SELF only at six

In the ICI example in (23-a) as well as in the ICC example in (23-b), PRO receives an interpretation that includes Hans but also other people. If the subject gap in the second conjunct were due to ellipsis or some other process, such a relation would be very unexpected. ${ }^{12}$

\subsection{The derived coordination analysis}

In this section, I will propose a theory that derives the seemingly contradictory properties of the ICC construction. In Section 2 we have seen the major puzzle that must be solved: Even though the construction looks like a coordinate structure on the surface, the most reliable tests we have indicate that the relation is in fact a subordinate one. In Section 3, we discussed two ways out of this dilemma: First, we can simply state that our tests seem to be inconclusive and abandon them altogether or we can swallow the bitter pill and say that despite everything we see on the surface, the construction is in fact subordinate. Neither option seems particularly attractive at this point. The first option seems not really justified given that the tests do a relatively good job in other parts of the syntax. And, as we have seen in Section 3, the second one needs a number of additional non-trivial stipulations and still cannot derive the fact that some tests seem to indicate a coordinate relation after all.

The analysis that I will put forward in this section pursues a middle way. We have seen that the construction at hand combines properties of coordinate and subordinate constructions at the same time. I argue that we should take this observation at face value and try to derive it in a step-by-step fashion. The core idea is that the standard syntax of coordination following Munn (1987), Zoerner (1995), Johannessen (1998) and much subsequent literature allows for a derivation in which a clause is base-generated as a subordinate clause but, later on, is

12 An anonymous reviewer remarks that while s/he agrees that partial control is possible in ICCs, Split Control seems to be impossible. I have nothing to say about this difference and I would hope that it emerges out of a general theory how the different types of control are actually derived. On Split and Partial Control in general see Landau (2000, 2004, 2008, 2013). On Partial Control in German, see Pitteroff et al. (2017). 
promoted to the specifier of a coordination phrase. Thus, the relation between these two clauses is a subordinate one at the beginning of the derivation and a coordinate one at the end.

In the case of ICCs, we observe that, semantically, the relation between the first and the second clause is a predicate-argument relation. The crucial assumption is that this semantic asymmetry has a direct syntactic correlate. A clause that has the semantic properties of the complement clause is syntactically basegenerated as a complement clause. ${ }^{13}$ Thus, the position of the complement clause of an ICI and the base position of an ICC is the same position of a regular complement clause embedded under a control verb. The second clause of an ICC is base-generated low in the tree but, throughout the derivation it may, however, be promoted to a conjunct position. ${ }^{14}$

A Derivation of ICCs:

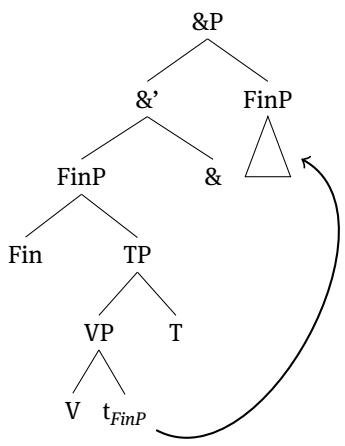

This movement step may seem unusual at first but it has been argued in Weisser (2015a) that the movement to the specifier of an \&P does not violate any kind of locality constraints. It moves to a specifier and leaves a c-commanded trace (or copy).

The only somewhat unusual assumption, in the case at hand, is that the specifier of the coordination phrase that is generated by this movement step is lin-

13 Given that the second conjunct of an ICC is an argument, this derivation is even enforced by Baker's (1988) Uniformity of Theta-Assignment Hypothesis (UTAH), which requires arguments with the thematical relationship to be base-generated in the same position regardless of where they appear on the surface.

14 An anonymous reviewer points out that this makes the prediction that in ICCs the second conjunct does not form a constituent with the conjunction to the exclusion of the first one. This is an interesting observation but at this point I cannot come up with a way of proving or disproving this consequence of the theory since typical diagnostics of constituency with coordination in German such as conjunct extraposition or floating coordinators (see Zhang 2010 for discussion) do not seem to apply with ICCs. 
earized to the right of its head. This, I argue, is however not a syntactic matter. By standard assumption, the linearization in general is not part of the syntax but of the post-syntactic module. Thus, in the case of the ICCs, in the syntax, the complement clause is simply moved to Spec\&P. In the course of the postsyntactic linearization process, the standard rule of linearization in German will be overwritten by the semantic or pragmatic meta-principles that have an impact on the linearization of coordination phrases. It is known, for example, that the order of clauses in clausal coordination always reflects the order of events in real time (see Jakobson 1971). This can be captured by assuming that there is something like the Temporal Iconicity Principle which can overwrite the default linearization. In the case at hand, I assume a similar meta-principle that can overwrite the default linearization for pragmatic reasons:

Ordering Principle of Implications:

The premise of an implication precedes its consequence.

The underlying idea is this: The syntax generates a binary branching tree which does not convey any linear information. A specifier c-commands its head as well as its complement but there is no information whether it precedes it linearly. This information is added in the postsyntax by a linearization algorithm which translates c-command into precedence relations. This algorithm usually acts on the basis of default orders specified for a given language (or in some cases even universally). In German for example, specifiers by default are located to the left of their heads. But in some cases, pragmatic principles such as (25) above can kick in and force the linearization algorithm to change its output in order to match more important restrictions. In this case, the specifier of an \&P is linearized to the right of its head since it is the consequence of an implication.

After the subordinate FinP has moved to the specifier of an \&P, the syntactic derivation proceeds as usual. The Top/Foc-head is merged which can, in the case of a matrix clause, provide for a prefield position. This prefield position can then be filled by means of movement (see next section). Finally there is the ForceHead that hosts the clause-type feature. If the whole clause is subordinate by itself, nothing happens. But if it is a matrix clause, the Force-head inherits a respective feature to the Fin-head in its local domain. This inheritance relation is based on the idea introduced by Chomsky $(2007,2008,2013)$ that non-phase heads receive their features by inheritance from the phase-heads above them. Intuitively, we can say that the highest head Force ${ }^{0}$ passes on the information whether the clause is a matrix clause or whether it is embedded into another clause. ${ }^{15}$ Since

15 See Rizzi and Shlonsky (2006), Rizzi and Shlonsky (2007); Chen and Corver (2013) for the necessity of feature inheritance in a split- $\mathrm{CP}$ approach. 
there are two coordinated FinPs, both receive Force's features and, as a result, attract the verbal head from lower in the tree. This is illustrated in (26).

Feature Inheritance in the case of ICCs:

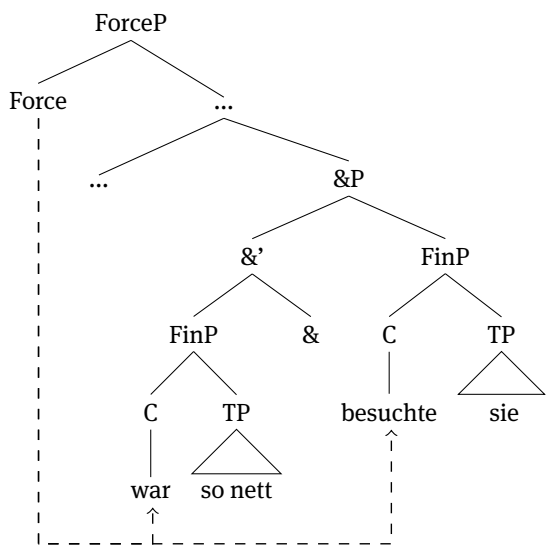

This feature inheritance achieves several things at a time. First, it explains why both conjuncts are V2-clauses even though one of them started out as a subordinate complement clause. Matrix clauses in German have their verb head-move to Fin $^{0}$. Second, intuitively speaking, it turns a nonfinite verb into a finite one. This happens automatically because of the movement into the position of the finite verb. Assuming a postsyntactic realizational model such as Distributed Morphology, I take finiteness to be not an inherent property of verbs but rather as an epiphenomenon of (a) the $\phi$-features the verb possesses and (b) its syntactic position. Verbs that remain low in the tree (e. g. in their base position or move only to $v$ ) in German typically appear in the infinitive or in the perfect participle form. I follow Salzmann (2017) in assuming that the infinitive is some kind of default form that occurs when the verb in question does not appear with functional morphemes such as $\mathrm{T}$ or Fin. Verbs that move to $\mathrm{T}^{0}$ or further to Fin $^{0}$, however, are finite. Head-movement of the verb obligatorily proceeds through $v$ and $\mathrm{T}$, thereby picking up $\phi$-features on $\mathrm{T}^{16}$ Once the verb lands in Fin ${ }^{0}$, it will eventually be realized in its finite form since it has (a) the right kind of features and (b) is located in a position associated with finiteness. A verb that remains in

\footnotetext{
16 It is sometimes assumed that T does not exchange $\phi$-features with PRO. However, I do not see a reason to depart from the default assumption that $\mathrm{T}$ and the subject enter into an Agree relation. In regular control clauses, we cannot tell whether T has PRO's $\phi$-features or not since $\mathrm{V}$ does not head-move to T. But since it has been shown in Sigurðsson (2008) that PRO receives case marking in some cases, I take it that there is indeed a licensing relation between PRO and T and therefore, I take it to be a feasible assumption that T has PRO's $\phi$-features available.
} 
its base position as in ICI constructions is eventually realized as nonfinite since it (a) does not have any $\phi$-features and (b) is not in a position associated with finiteness. Using the formalism of Distributed Morphology, we can capture this intuition with context-sensitive spell-out rules. An alternation between a nonfinite (27-a) and a finite form as in (27-b) could be captured with spell-out rules as in (28):

a. Hans war so nett, sie zu besuchen.

Hans was so nice her to visit

b. Hans war so nett und besuchte sie.

Hans was so nice and visited her.
a. $\sqrt{\text { besuch }} \leftrightarrow /$ besuchen/
b. $\sqrt{\text { besuch }} \leftrightarrow /$ besuch-/ / Fin ${ }^{0}$
c. $\quad\{$ past $\} \leftrightarrow /$-te- $/ /$ Fin $^{0}$

On the basis of these spell-out rules, it is clear why the verb in an ICC occurs as finite and a verb in an ICI occurs as nonfinite. (29) and (30) illustrate the positions of the verbs respectively. In (29), an ICC construction, the verb has moved to Fin and is therefore realized as finite. In (30), an ICI construction, the verb remains low (it may have moved to $v$ ) but crucially, it is not in the immediate context of functional material such as T or Fin and will therefore be realized with the infinitive Vocabulary Item in (28-a).

(29)

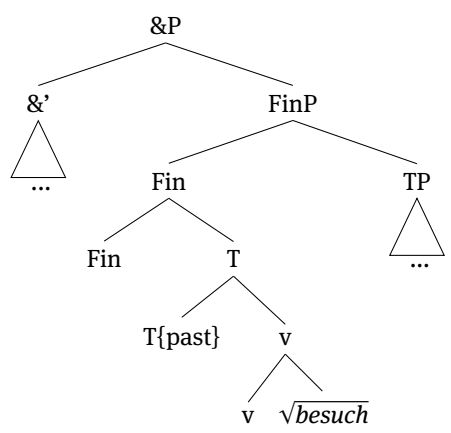

(30)

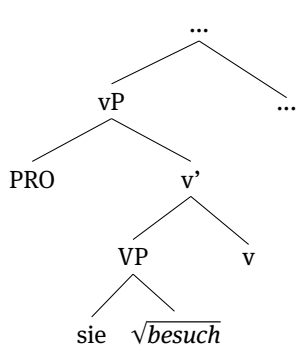

So, to sum up, the final syntactic structure of an example like in (27-b) looks like the following: 
(31)

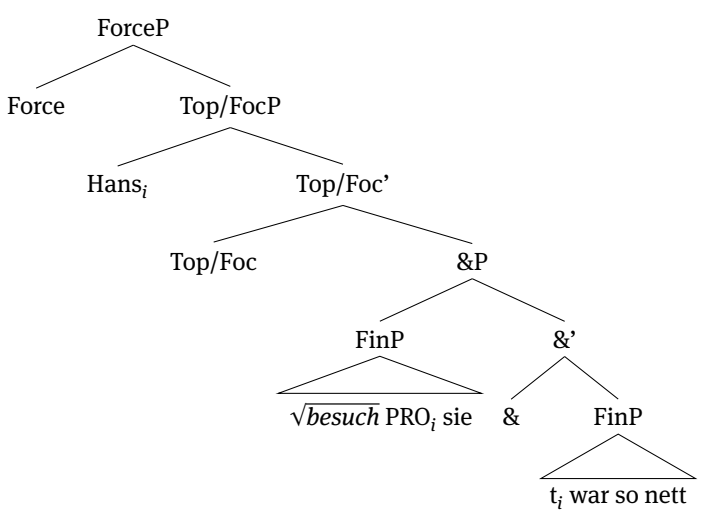

In the postsyntax then, two important things happen. First, linearization translates the syntactic hierarchy into linear precedence. Unlike in most cases in German, the specifier of the conjunction phrase is linearized to the right in order to obey the principle in (25). The two conjuncts are the premise and the consequence of an implication and therefore the linearization of the conjunction phrase is reversed. The complement precedes the conjunction and the specifier. The second important thing is vocabulary insertion. Since both verbs have moved to $\mathrm{Fin}^{0}$ via $\mathrm{T}$, they have all the relevant features and can be expressed with finite verb forms. The vocabulary items of $\mathrm{V}$ and $\mathrm{T}$ in the second conjunct are the ones in (28-b) and (28-c). After linearization and vocabulary insertion, the resulting structure is the surface string (with $\varnothing$ being the realization of PRO):

$$
[\text { Hans }]>[\text { war so nett }]>[\text { und }]>[\text { besuchte } \varnothing \text { sie }]
$$

\subsection{Deriving the seemingly contradictory properties of the ICC}

In the preceding section, we saw that the ICC starts out as a subordinate clause and only in the course of the derivation, it is turned into a coordinate clause by movement to Spec\&P. Based on this derivation, we can account for the seemingly contradictory properties of the construction. All the subordinate properties that we observed in Section 2.1 follow from operations early on in the derivation whereas all the coordinate properties follow from late operations or output requirements.

Starting out with the properties suggesting a subordinate relation between the two clauses. In Section 2.1 we saw that a variable or an anaphor in the second conjunct can be bound by an element in the first conjunct. Similarly, an adverb (or negation) in the first conjunct takes scope over the second conjunct. Finally, 
in Section 3.1, the assumption was made that the two subjects of the clauses are obligatorily the same because there is a big PRO element contained in the second conjunct that is licensed by the subject of the first conjunct. Abstractly, we thus have three properties that suggest that elements in the first conjunct c-command elements in the second conjunct. Given the derivation in the preceding section according to which the second conjunct starts out as a subordinate clause, this behavior receives a straightforward explanation.

As for binding, it has been known that we find cases where anaphors and variable pronouns are only bound at an early stage of the derivation. These cases are well formed even though the respective items do not seem to have a binder on the surface structure.

[Which picture of himself $\left.]_{i}\right]_{e}$ do you think that Bill ${ }_{i}$ likes e best?

(Belletti and Rizzi 1988: 314)

Belletti and Rizzi (1988) conclude that it is possible that anaphors and variables can be bound at early stages of the derivation. This is exactly what we find with ICCs. In the base position of an ICC, a variable pronoun is c-commanded by its host in the matrix clause. Hence, it may be bound. The fact that subsequent movement of the whole ICC to Spec\&P destroys the c-command relation does not affect the binding relation. ${ }^{17}$ In other words, the movement of the complement to Spec\&P counterbleeds the binding relation.

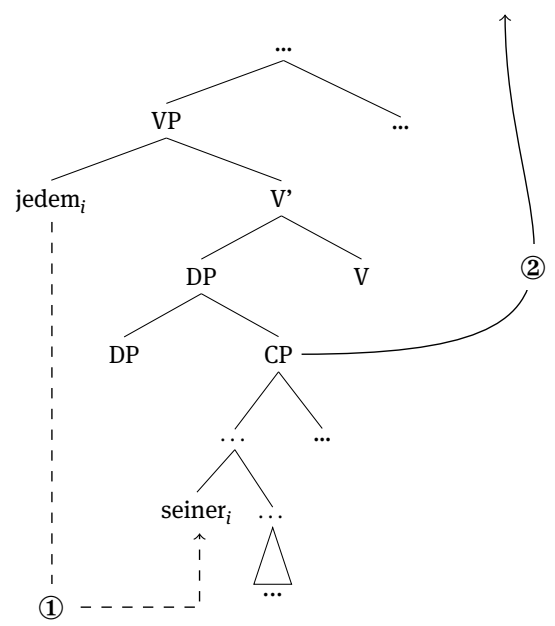

17 A different implementation of binding that is also compatible with the analysis I present is that binding applies postsyntactically on LF and the syntactic movement process dislocating the $\mathrm{CP}$ to Spec\&P is reconstructed for the purpose of binding. 
The binding relation in (34) (indicated by the dashed line) is established (step (1) before movement of the CP into a higher position in the tree (indicated by the solid line (step (2))). Hence, c-command is given and the configuration is grammatical.

The second property, namely the fact that adverbs and negation can take scope over the second conjunct, can be derived in similar fashion. As with binding above, we know that adverbs and negation can take scope over elements have escaped their c-command domain in the course of the derivation. Take the following examples:

(35) Wem hat [eine Ohrfeige zu geben] Hans vergeblich versucht?

Whom has a slap to give Hansin.vain tried

'Who has Hans tried to slap in vain?'

(Grewendorf 1989: 61)

(36) Sich selbst die Haare zu schneiden hat Peter wohl noch nicht

REFL SELF the hair to cut has Peter probably yet not

versucht.

tried.

'Peter probably hasn't tried to cut his own hair yet.'

In (36), the clause that is selected under the control verb versucht 'tried' is focused and thus moved to the prefield. Still we find that (i) the adverb wohl 'probably' as well as the negation nicht take scope over the preposed clause. Standardly, this is taken to show that certain movement steps can be undone (reconstructed) for the purposes of semantic scope of adverbs and negation. Thus, again, with the Derived Coordination Account, these properties basically fall out as expected.

Another property that the example in (36) shows is that PRO, the embedded subject, does not have to be in the c-command domain of its licenser on the surface. It can be licensed at a certain point of the derivation and if subsequent movement steps destroy the configuration in which PRO was licensed, that does not affect the licensing. We can therefore assume that, in ICC examples, PRO is licensed in the very same way as in ICIs. And, as can be seen in (37), the fact that the clause it is contained in is moved away subsequently does not affect the licensing. ${ }^{18}$

18 Again, it does not play a role how this licensing is accomplished technically. If it were an instance of actual binding of PRO as traditionally assumed (e. g. as in Landau 2000, Landau 2004) or if it were derived by means of Agree as in Fischer (2016). 


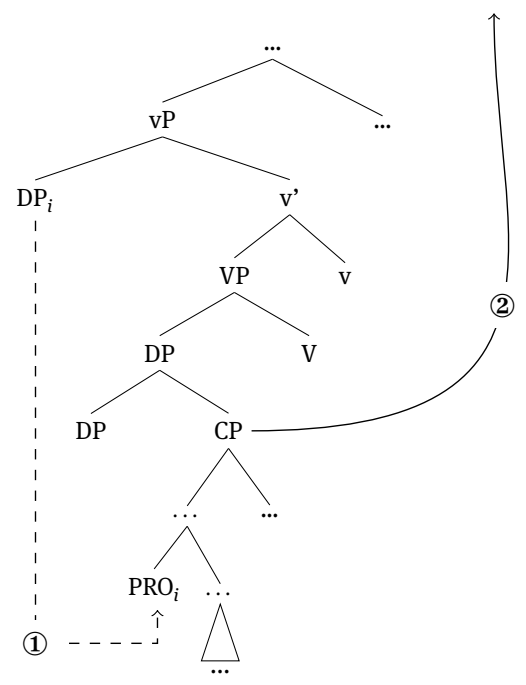

The extraction property of ICCs can be explained under the proposed analysis as well. In Section 2, we saw that extraction from ICCs can avoid the Coordinate Structure Constraint. For the sake of concreteness, I have restated Ross' (1967) version of the CSC in more theoretical terms.

(38) Coordinate Structure Constraint (updated):

In a structure $\left[\& P A\left[_{\&^{\prime}} \& \mathrm{~B}\right]\right]$, movement (out) of either $\mathrm{A}$ or $\mathrm{B}$ is prohibited.

Given this definition, we can envisage a derivation that extracts out of only one conjunct without a violation of the CSC. The underlying intuition is the same as above. The subordinate properties follow from operations that apply early in the derivation, i. e. prior to the formation of a coordinate structure. It is the same with asymmetric extraction. It is possible to extract from only one conjunct as long as no coordinate structure is formed. The tree in (39) illustrates the relevant structure. The crucial point of the derivation is when the matrix FinP has been merged with the coordination head. At that point in the derivation, $\mathrm{FinP}_{1}$ contains two elements that are to undergo movement (i. e. the element that wants to move to the first position (wh for exposition) and FinP $_{2}$ ). 
(39)

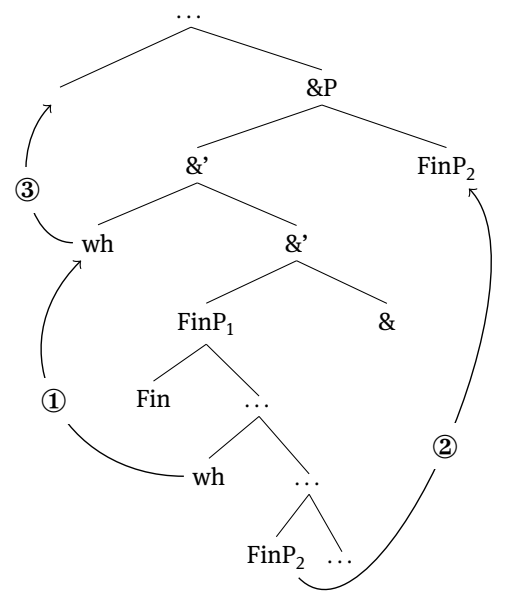

If FinP $\mathrm{P}_{2}$ undergoes movement first, then the coordinate structure is created and $w h$ is trapped by the CSC. If the wh-element moves first however, then the derivation can proceed successfully. As a first step, the wh-element is extracted to an intermediate specifier of the coordination head. ${ }^{19}$ After that the complement clause moves to Spec\&P creating a coordinate structure. From now on, extraction from each conjunct is prohibited. But, crucially, at that point of the derivation, the whelement has already been moved out of the conjuncts. Thus, it may subsequently move further up in the tree (step (3), either triggered by a wh-feature (in matrix contexts) or an edge feature (in embedded contexts). ${ }^{20,21}$

19 This is basically equivalent to saying that \&P is a phase - see Reich (2007) for the same assumption.

20 Given such a derivational view of the CSC, the same derivation must, of course, be prohibited with symmetric (i. e. base-generated) coordination. As shown in Weisser (2015a), this can be done by invoking the Merge-over-Move Principle introduced by Chomsky (1995, 2000); Frampton and Gutmann (1999); Hornstein (2001, 2009); Castillo et al. (2009); Boeckx et al. (2010); Drummond (2011). In the case above in (39), two instances of movement compete with each other. However, in the case of base-generated, symmetric coordination, an instance of Move (i. e. the wh-element) competes with an instance of Merge (i. e. External Merge of the specifier of \&P). The Merge-overMove Principle requires Merge to apply first which completes the \&P. As a result, the CSC prohibits subsequent movement out of the lower conjunct.

21 As mentioned in Section 2.1, not all speakers equally accept cases of asymmetric extraction from one of the conjuncts. And while I do not have a fully articulated analysis of speaker variation wrt. the question of extraction, we could speculate that some speakers seem to view the Coordinate Structure Constraint as more of a representational constraint that penalizes asymmetric cases of extraction from structures that look like coordinations on the surface. Since the structure is coordinate on the surface, a representational version of the CSC is presumably violated by the movement. 
After illustrating how the subordinate properties of the ICC construction are derived, we can briefly address the coordinate properties of the construction. Although ICCs pattern with ICIs in many key properties, we have seen that some properties might lead us to think that the construction is in fact also coordinate in nature.

First, we can straightforwardly account for the occurrence of the conjunction und which is pronounced in $\&^{0}$ in very much the same way it would have been in regular, base-generated coordination.

Second, we can account for the fact that the second conjunct of an ICC, unlike with an ICI, has its verb in initial position. We saw in Section 4.1 that this follows from feature inheritance of Force down onto the Fin-head, which then attracts the verbs.

Third, the analysis also accounts for the fact that ICCs have a very strict word order. The second conjunct cannot be extraposed into the first one. This follows from the Coordinate Structure Constraint without further ado. Once the coordinate structure is built, no conjunct may be moved (i. e. extraposed) anymore.

Finally, if we assume that ATB-movement involves asymmetric extraction from out of the first conjunct and late deletion on PF as argued for in Salzmann (2012), then we can assume that even a derived coordination structure can feed ATB-movement.

\subsection{Interim summary}

So, to summarize, I have proposed a straightforward analysis to account for ICC constructions. The major challenge of this account was that the ICC construction, which is coordinate on the surface, seems to exhibit all the major properties of subordinate constructions. It patterns with its infinitival counterpart, the ICI with respect to binding of variables and anaphors, extraction and scope of negation and adverbs.

The core idea of the account was to take the seemingly contradictory properties of the construction at face value and attribute them to derivationally related representations. ICC constructions are in fact derived on the basis of their ICI counterpart.

We have seen that the current assumptions about the structure of coordination in principle allows us to move a subordinate clause to a position where it counts as a proper conjunct. The relation of the ICC and the ICI constructions are a strong case in point as they show both representations overtly. In principle, however, nothing hinges on whether the underlying representations are in fact gram- 
matical sentences. If movement of the subordinate clause to the second conjunct position would have been obligatory with ICCs, then we would have never been able to observe the underlying representation. As we will see in the next section, this in fact allows us to account for a number of other asymmetric coordination constructions. We will see that the famous case of the German SLF-construction can be derived in very similar fashion.

\section{Other cases of asymmetric coordination}

The previous sections provided an in-depth discussion of what I called the Implicational Complement Coordination construction. Although formally a coordinate construction, the ICC patterns with its infinitival counterpart with respect to almost all syntactic tests. For this reason, I proposed an analysis that tries to relate the two constructions by saying that one (i. e. the ICC) is derived on the basis of the other (i. e. the ICI). As a result, we were able to derive the seemingly contradictory properties of the ICC construction.

In this section, we will broaden our views a little, just to see that a number of other asymmetric coordination constructions in German, all of which are notoriously problematic for syntactic theorizing, can be derived in similar fashion. I will mainly focus on the so-called SLF-coordination construction in German, which has received quite some attention due to its unclear status in between subordination and coordination. It will be shown that SLF-constructions exhibit similar behavior with respect to the tests concerning syntactic dependencies. And based on this observation, I will argue that even though these constructions lack an obvious infinitival counterpart of the ICI type, they should nevertheless be derived in the same way.

\subsection{The syntactic properties of SLF-coordination}

The term SLF-coordination was coined by Höhle $(1983,1990)$ and refers to a specific asymmetric coordination construction in German (and related languages such as Dutch, see Bjorkman 2013a). Pretheoretically, the construction is characterized by the conjunction of a V2- and a V1-clause. Crucially, the V1-clause, which is always the second conjunct, does not contain a subject. Rather, its subject is coreferent with the subject of the first conjunct. This is possible even if that subject is deeply embedded in the first conjunct and should not be able to take scope over the conjunction. 
(40) [Da stellt sich jemand vor die Mikrofone] und [tut so, als There stands REFL someone in.front.of the microphones and does so as könne er was erklären]. could he what explain 'Someone stands in front of the microphones and acts like he could explain something.'

(Reich 2008: 282)

(41) [In Mainz fährt Heinz am Abend los] und [kommt am Morgen in In Mainz goes Heinz in.the evening PRT and comes in.the morning in Bonn an]. Bonn PRT 'Heinz leaves in Mainz in the evening and arrives in Bonn in the morning.' (Heycock and Kroch 1994: 258)

This construction has received quite some attention and different proposals have been made in the theoretical literature how syntactic behavior should be handled, see e. g. Höhle (1983, 1990, 1991), Heycock and Kroch (1994), Büring and Hartmann (1998), Johnson (2002), Fortmann (2005), Sternefeld (2007), Barnickel (2017).

As many of the authors above have observed, this construction exhibits a number of clear-cut syntactic asymmetries that are reminiscent of the ones found with ICCs in Section 2.

First, we find that, as with ICCs, there is a subject gap in the second conjunct that is obligatorily interpreted as identical with the subject of the first conjunct. Having two different subjects is impossible:

(42) *In Mainz fährt Heinz am Abend los und kommt Tom morgens in In Mainz goes Heinz in.the evening PRT and comes Tom in.morning in Bonn an.

Bonn PRT

'Heinz leaves in Mainz in the evening and Tom arrives in Bonn in the morning,'

Secondly, we observe that as with ICCs, an anaphor or a variable pronoun in the second conjunct can be bound by an element embedded in the first one (43).

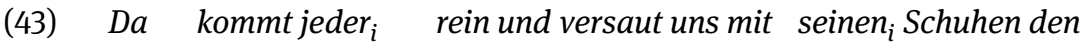
There comes everyone in and soils us with his shoes the Teppich.

rug.

'Everyone ${ }_{i}$ comes in and gets our rug dirty with his ${ }_{i}$ shoes.' 
Third, we find the exact same behavior of negation and other adverbs as in ICCs. Again, negation and other adverbs can take scope over the second conjunct even if they are deeply embedded into the first one.

(44) An einem Sonntag kam Katharina noch nicht nach Hause und war On a sunday came Katharina yet not to home and was betrunken.

drunk

'On a sunday, Katharina didn't came home drunk yet.'

(Büring and Hartmann 1998: 182), slightly modified

(45) Gestern kam Peterwohl nach hause und war betrunken.

Yesterday came Peter probably to home and was drunk

'Yesterday Peter came probably home drunk.'

In (44), the only available reading is that the negation takes scope over the second conjunct: On a sunday, it was not the case that Katharina came home and was drunk. An alternative reading, in which the negation takes scope over the first conjunct only is not possible: ${ }^{*}$ On a sunday, Katharina didn't come home and she was drunk. In (45), the adverb wohl 'probably' must take scope over the second conjunct as well: Yesterday, it was probably the case that Peter came home and he was drunk is the only possible reading.

Finally, when looking at extraction, we find that SLF-coordination seems to allow asymmetric extraction from the first conjunct. ${ }^{22}$ If we adopt the assumption, shared by most, that the structure of both clauses is symmetrically verb-initial, then we find that the prefield is occupied by an element asymmetrically extracted from the first conjunct.

(46) Einen Wagen kaufte Hans und baute sofort einen Unfall.

A car bought Hans and built immediately an accident 'Hans bought a car and caused an accident immediately.'

(Büring and Hartmann 1998: 176)

We thus see that SLF-coordination behaves very similar to ICC constructions. In both cases, the standard tests for clausal relations indicate a subordinate

22 Note however that, unlike with ICCs, asymmetric extraction is not possible from the second conjunct:

(i) `Einen Wagen ging Hans zum Händler und kaufte.

A car went Hans to salesman and bought.

'A car, Hans went to the salesman and bought.'

I will come back to this difference between SLF-coordination and ICCs below. 
relationship whereas the morphosyntanctic form looks coordinate on the surface.

\subsection{Existing approaches to SLF-coordination}

Unlike with ICC coordination, which has not yet received a theoretical treatment, quite a few authors have addressed the phenomenon of SLF-coordination. For limitations of space, I can of course not do justice to all the accounts proposed which is why I can only briefly address how the authors tackle the question of how the seemingly contradictory properties of the construction can be derived. For closer inspection of each of these accounts, the reader is referred to Barnickel (2017).

Since we have seen that SLF-coordination exhibits properties of both subordination and coordination, it is not surprising that the existing approaches can be grouped into to camps, i.e. the ones that adopt a syntax that is underlyingly coordinate and the ones where the syntax is underlyingly subordinate. Based on this distinction, the two analyses, of course, struggle to explain certain properties of the construction.

Büring and Hartmann (1998) and Reich (2008, 2009) both adopt a subordination analysis where the second conjunct is adjoined to the matrix clause. Both accounts must therefore make quite stipulative assumptions about the nature of the conjunction und itself, which, in SLF-coordinations, necessarily behaves very differently from its regular clause-combining conjunction. In Reich's (2008, 2009) account, for example, the und used in SLF does not select for its arguments, whereas in regular coordination it does. Similarly, it is not clear why SLF-adjuncts do allow for Gapping whereas regular adjuncts do not.

The coordinate accounts such as Heycock and Kroch (1994), Höhle (1990), Johnson (2002) and Fortmann (2005) are forced to make very non-standard assumptions about the nature of coordination in these cases. The first apparent problem that coordination accounts face is of course the difference in word order. The first conjunct is a V2-clause whereas the second conjunct is a V1-clause. One way to approach this problem is to assume that unlike categories can be conjoined. In Heycock and Kroch (1994), I' and C' categories are conjoined whereas in Sternefeld (2007) CP and VP are conjoined.

Second, the existing coordination approaches naturally struggle to derive the extraction properties as well as the binding and scope facts. In Johnson's (2002) account, the Coordinate Structure Constraint is relativized to A'-movement, and, by stipulation, it is an instance of invisible A-movement which, in Collins' (2005) terms, smuggles elements to a position outside of the coordination phrase. In that position, the smuggled elements can asymmetrically take scope, bind, and 
A'-move. However, no additional evidence for (i) the invisible movement step or (ii) the relativization of the Coordinate Structure Constraint are given in this system.

Sternefeld (2007) presents a slightly different account according to which coordination structures and subordination structures are both present in SLFcoordination in one way or the other. In my account, this will be achieved by derivationally relating the two structures with one another. In Sternefeld's (2007) account this relation between the two structures remains somewhat unclear. He states that an asymmetric coordination structure must be converted into an adjunction structure but, unfortunately, the actual mechanics of this conversion operation are not addressed. Based on what we have said for ICC constructions in the preceding sections, we can conclude that this is in fact the correct intuition. However, instead of assuming a somewhat mysterious conversion operation, we will see that it is possible to relate the two different syntactic structures derivationally. As with ICC constructions, the subordinate structure is transformed into a coordinate one by movement.

\subsection{Transferring the analysis to SLF-coordination}

Given the clear parallels between the two constructions we saw in the previous sections, it seems adequate to try and transfer the analysis proposed for ICCs to SLF-coordination. The only challenge that we need to overcome is that SLFcoordination constructions of course lack their immediate infinitival counterpart. Nevertheless, it seems promising though to assume that the clause that will eventually become the second conjunct of the construction starts out as a subordinate clause. In doing so, we can account for the whole range of properties that suggest a subordinate relation between the clauses in question. However, the difference is that with ICCs, the subordinate clause was an argument of the matrix verb (or DP-internal argument) whereas with SLF-coordination we need to assume that the subordinate clause starts out as an adjunct. We could thus imagine that the SLFconstruction in (47-a) has a paraphrase like (47-b):

(47) a. In den Wald ging der Jäger und fing einen Hasen. In the woods went the hunter and caught the hare 'The hunter went into the woods and caught the hare' (Wunderlich 1988: 289)

b. In den Wald ging der Jäger, einen Hasen fangend. In the woods went the hunter the hare catching 'The hunter went into the woods catching the hare' 
The resulting structure could thus look like (48). The subordinate clause starts out as an adjunct to VP.

(48)

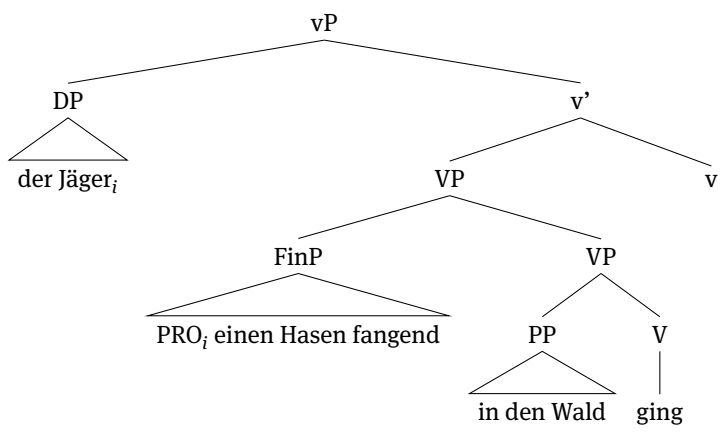

As in the case of an ICC, the subordinate clause contains a PRO that is coindexed with the matrix subject. As in regular cases of adjunct control, the PRO is controlled by the subject which it is c-commanded by (49).

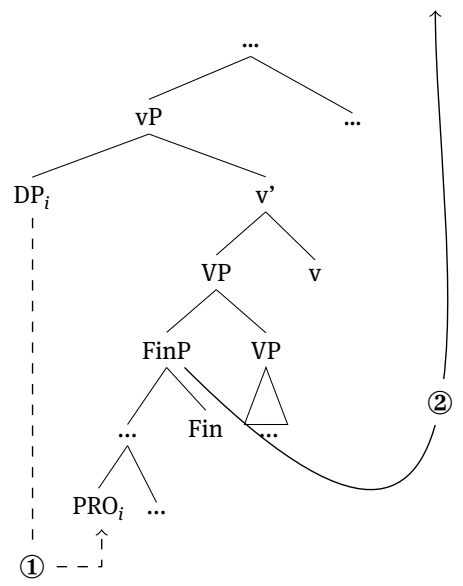

Similarly, if matrix clause contained a negation or an adverb, which is presumably adjoined to vP or higher, then they could take scope over the subordinate clause. If there is a bound variable or an anaphor in what will ultimately become the second conjunct, it can, at this stage of the derivation be bound by the subject of the matrix clause.

Ultimately, once the matrix clause is built up to the FinP-level, the \&-head is merged, taking the matrix FinP as its lower argument. And then, finally, the adjunct FinP moves to Spec\&P and completes the coordination (50). 


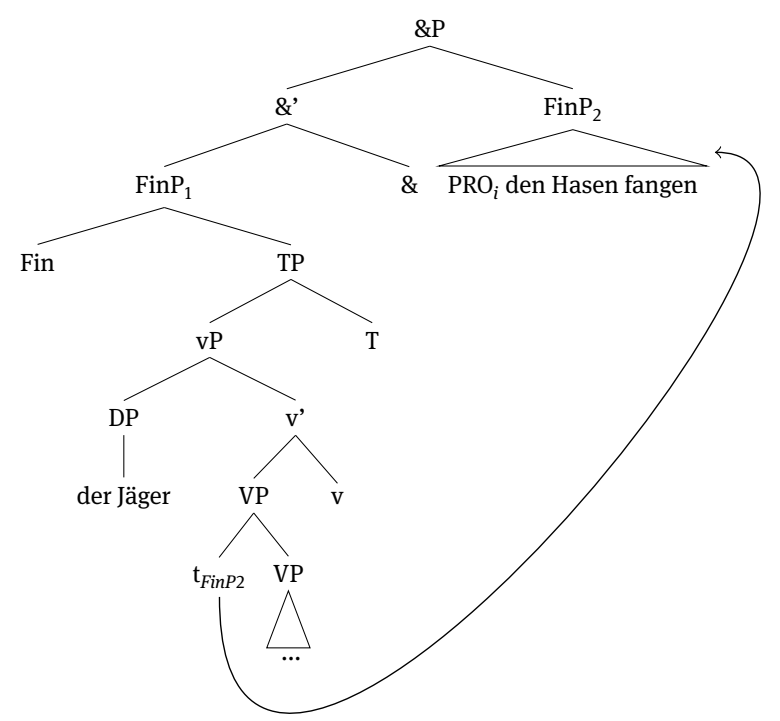

Again, the specifier of the \&P will eventually be linearized to the right of the head since there is, by assumption, a meta-principle that requires the order of the conjuncts to reflect the order of events in real time.

As with the case of the ICCs, there will then be a Force-Head that inherits its clause type features down on both Fin-heads simultaneously triggering V-to-Fin movement in the case of a matrix Force. The prefield will be filled by an element asymmetrically extracted out of the first conjunct. Note that, in the case of ICCs, asymmetric extraction was possible from either the first or the second conjunct. This followed from the fact that asymmetric extraction could take place before the coordination structure was created. Before the creation of the coordination structure, the first conjunct was a matrix clause whereas the second conjunct was, at the point of the derivation, a complement clause. Extraction from either a matrix clause or a complement clause is grammatical. In the case of SLF-coordination, extraction is possible only from the first conjunct. This follows without further ado. Prior to the creation of the coordination structure the second clause is an adjunct and subsequently it is a proper conjunct. Both conjuncts and adjuncts are opaque for extraction. At no point in the derivation is there a possibility to extract from the second clause of an SLF construction.

Summing up, we find that the properties of SLF-constructions can be derived by assuming that this coordination structure is derived on the basis of a subordinate structure. Unlike the ICC construction, the SLF-coordination has no obvious subordinate structure that can surface as a grammatical sentence. This, however, does not constitute a serious counterargument against an analysis along those 
lines. In many analyses, underlying structures are assumed to account for syntactic properties even though these structures never surface as such.

\section{Remaining issues}

In this section, I want to highlight a number of remaining issues that arose in the course of the discussion.

\subsection{The size of the conjoined category}

In the preceding sections, I presented two analyses of asymmetric coordination constructions in German. In order to derive the syntactic asymmetry between the two conjuncts in both constructions, I made use of a novel kind of derivation: The movement of a subordinate clause into the position of a proper conjunct. In doing so, I was able to provide an explanation for the asymmetries with respect to binding, semantic scope and extraction. The question that arises, is why this kind of derivation is not found more often. In both cases at hand, it was clauses of the specific size of a FinP that could undergo this transformation. So, why don't we find this kind of movement with verbal projections of a different size or even with DP-, AP- or PP-coordination?

Let us first address the question why FinPs can take asymmetric readings whereas full clauses, i. e. ForcePs in my terminology cannot. We find that any clause which has an element in Force ${ }^{0}$ such as dass-clauses or even infinitives introduced by the complementizer um do not allow for an asymmetric derivation. It was noted by Bjorkman (2013a), Bjorkman (2013b), for English, that what she calls conjunction of CPs cannot take an asymmetric reading whereas conjunction of TPs can:

a. The newspaper reported $\left[_{C P}\right.$ that the government was elected] and $\left[_{C P}\right.$ that there was a riot]. $\quad \rightarrow$ Two unrelated events

b. The newspaper reported that $\left[_{T P}\right.$ the government was elected] and $\left[_{T P}\right.$ there was a riot]. $\rightarrow$ Two related events (one caused by the other) (Bjorkman 2013a: 396)

Bjorkman (2013a) provides us with an elaborate semantic theory of why this generalization holds. She argues that the semantic denotation of and requires a certain semantic type in order to yield an asymmetric reading. When and conjoins two items that are semantically speaking situations, then and yields an asymmetric 
reading. The reason for this is that situations are objects with temporal extension and thus they can be ordered with respect to each other. ${ }^{23}$ However, conjoining two full clauses will yield no ordering effect. Bjorkman (2010) argues that full clauses are either truth-values themselves (in the case of matrix clauses) or abstractions of propositions (in the case of embedded clauses) and thus are not of orderable type. We therefore have an explanation why we do not find asymmetric coordination of CPs but we do with TPs in Bjorkman's system.

I think this solution can be adapted to our purposes at hand without further ado. In fact, Bjorkman (2013b) even notes with respect to asymmetric coordination in Dutch and German that this "may indicate that speaking of TP vs CP coordination is an oversimplification and that a more fine-grained division of the left periphery is involved in coordination.” (Bjorkman 2013b: 6) This is exactly what we have done in Section 3. So, without going into the semantic denotation of each head in the left periphery, I think it is possible to assume that it is in fact the FinPhead which is of orderable semantic type and not TP (if there even is such a thing in German).

So, let us come back to the question of why it is impossible for DP or PP coordination to emerge in the same way. Based on what we said above, we are, in principle, facing two possible lines of argumentation. Either we can simply say that the other categories such as DPs, PPs, etc. are also not of the right semantic type. In other words, FinPs are the only thing that is orderable from a semantic point of view. This is a stipulation and even though it would probably possible to formulate it as part of Bjorkman's semantic theory of conjunction, it is not a priori clear that we can find independent motivation for it. But as long as nothing speaks against this option, it should be kept in mind as a valid possibility.

The second option is possibly more interesting as it in facts seeks to broaden the empirical basis of asymmetric coordination in other domains. Bjorkman notices that, for English, there are various other domains where the size of the conjuncts has an impact on how the relation between the conjuncts is interpreted. She gives the following minimal pair:
a. The officer and the lady
b. The officer and lady

The conjunction of two DPs in (52-a) can only be interpreted as two independent individuals. In the case of (52-b), where we have conjunction of something slightly

23 Cases of asymmetric coordination usually dubbed as Conditional Conjunction (see e. g. Culicover and Jackendoff 1997; Weisser 2015b) would presumably also fall into the set of asymmetric TP/FinP-coordination. 
smaller than DPs (maybe NPs), there we find an ambiguity as to whether the two conjuncts refer to the same individual or not.

Another domain is of course the vP/VP distinction in English. Bjorkman (2013b) argues that the former cannot have asymmetric properties whereas the latter can, resulting in phenomena alluded in the introduction:
a. This is the whiskey, he went to the store and bought. (Ross 1967: 168)
b. This is the stuff, the guys in the caucasus drink and live to be a hundred. (Lakoff 1986: 157)

It is beyond the scope of this paper of course to decide whether this option is the right way to go. It obviously raises the question why these cases of asymmetric coordination are not attested in German as far as I can see but it is definitely an interesting question for further research.

\subsection{Optionality of movement}

We have seen in Section 2 that ICC constructions freely alternate with ICIs, the infinitival counterpart. In the analysis, this was derived by saying that ICCs are derived from ICIs by means of movement. And since this movement step is, by assumption, optional, the alternation between the two constructions was derived. With SLF-coordination, it was noted that there is no immediate infinitival counterpart that comes to mind. We therefore assumed for the time being that movement in this case was more or less obligatory. This, of course, raises the question what distinguishes these two kinds of movements.

I would like to suggest that the answer to this question is something outside of syntax proper. In Section 4, I briefly alluded to the possibility that an SLFcoordination as in (54-a) was derived on the basis of an infinitival adjunct clause as in (54-b).

a. In den Wald ging der Jäger und fing den Hasen.

In the woods went the hunter and caught the hare.

'The hunter went into the woods and caught the hare'

Wunderlich (1988)

b. In den Wald ging der Jäger, den Hasen fangend.

In the woods went the hunter the hare catching

'The hunter went into the woods catching the hare.'

These kinds of infinitival adjunct clauses are only marginally possible in presentday German. In other Germanic languages, constructions of this sort are much 
more widespread. There might be various reasons why speakers of German dislike constructions of this sort. A straightforward one might be that the participle form of the verb in the adjunct clause is hardly attested in German anymore. In other Germanic languages, it is used for more purposes such as progressives and thus it might be in principle more readily available. ${ }^{24}$

But even though constructions of this sort are perceived as archaic or stilted, we can assume that syntactically, these clauses are well formed. If we follow this reasoning, we can assume that movement is not necessarily obligatory in the case of SLF-coordination. However, not undergoing movement is restricted to a formal, archaic register.

\subsection{The fusing-interpretation}

As Höhle (1983) has already observed, SLF-coordination in German is not unconstrained semantically. Höhle notes that cases of SLF-coordination always presuppose a natural immediate relation between the predicates involved. This intuition was refined by many, in particular by Reich $(2008,2009)$ who stated that the predicates involved in SLF-coordination necessarily be interpreted as one event. Two predicates that describe unrelated events or even states rather than events cannot form an SLF-coordination:

$$
\begin{aligned}
& \text { *In Deutschland wird Bier nach dem Reinheitsgebot gebraut und hat } \\
& \text { In Germany PASs.Aux beer to the purity.law brewed and has } \\
& \text { einen Gefrierpunkt von }-3^{\circ} \mathrm{C} \text {. } \\
& \text { a freezing.point of }-3^{\circ} \mathrm{C} \\
& \text { 'In Germany, beer is brewed in accordance to the Beer Purity Law and beer } \\
& \text { has a freezing point of }-3^{\circ} \mathrm{C} \text {.' }
\end{aligned}
$$

The present account provides a straightforward explanation for this. We have seen in Section 4 that coreference of the subject in SLF-coordination arises similarly as with ICCs, namely as the result of coindexation of PRO with the matrix subject. This coindexation process presupposes that the adjunct which will eventually become the second conjunct is base-generated below the subject.

24 An anonymous reviewer remarks that there are slight differences semantically between (54-a) and (54-b) in terms of the temporal order of events. While, in (54-a), the events are temporarily ordered sequentially, they are not in (54-b). I agree with the judgments of the reviewer at least for the minimal pair in (54). But to offer a tentative explanation for the semantic difference, I think it is likely that it is in fact the semantics of $u n d$ which adds the semantic component of temporal ordering (see the discussion of the semantics of the coordination in Section 5.1). 
This means that the adjunct is adjoined to v' or lower which in turn gives us the correct interpretation because then, the event variable of the second conjunct is base-generated in the scope of the first one. (56) illustrates the situation:

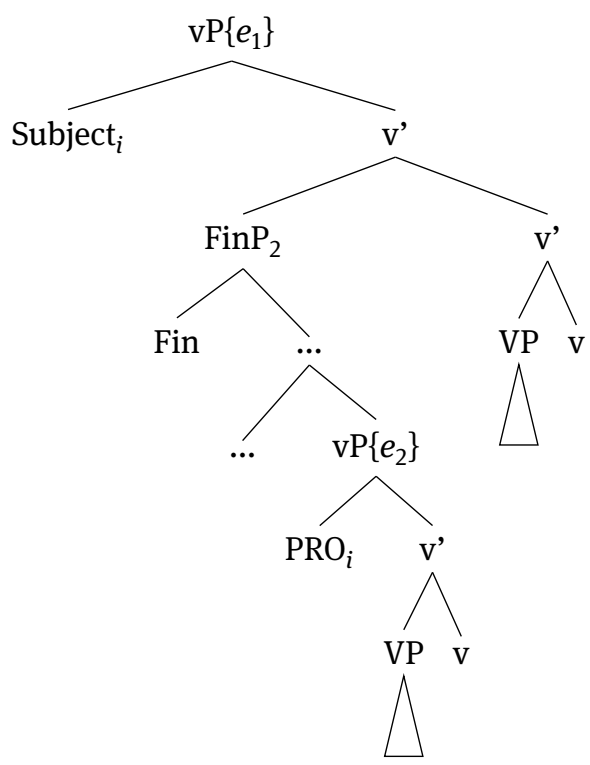

By standard assumption (see e. g. Hale and Keyser 1993; Kratzer 1996; Ramchand 2008; Truswell 2010), "if a constituent XP describes an event $e_{1}$ and if $e_{1}$ contains $e_{2}$ as a subevent, then XP contains a phrase YP which describes $e_{2}$." (Truswell 2010: 18) This is exactly the situation that we find in the base position of the adjunct. Thus, unlike many of the competing approaches to SLF-coordination discussion in Section 4.3, the present account has the additional benefit that it nicely ties in with the recent approaches cited above which seek to build the semantic event structure directly into the syntactic structure.

In the special case at hand, there is, of course, the additional complication that, at a later step of the derivation, the vP that describes $e_{2}$ is moved to a position that is no longer contained in the vP that describes $e_{1}$. However, this can be handled by means of reconstruction, because, as we have seen above, reconstruction might be necessary with respect to the semantic scope of adverbs and negation anyway. 


\subsection{Correlate es}

One final issue that needs to be addressed is the occurrence of correlate es with the verb wagen in the ICC construction. With the ICI, the occurence of the correlate es optional but with the ICC, it becomes obligatory.

a. Peter wagt (es), seiner Freundin einen Antrag zu machen. Peter dares it his girlfried a proposal to make

b. Peter wagt ${ }^{*}(e s)$ und macht seiner Freundin einen Antrag. Peter dares it and makes his girlfriend a proposal

A standard analysis (see e. g. Sudhoff 2003; Sudhoff 2016; Holler 2013; Frey 2016) is to treat the correlate es as a D-element which embeds the complement clause. Since the D-element is phonologically weak and cannot be receive stress, it can only be realized when its complement clause is extraposed. Thus an example like (57-a) with a correlate always involves extraposition. When the complement clause is moved to the prefield or not moved at all, the correlate is impossible:

a. Seiner Freundin einen Antrag zu machen wagt Peter ( $\left.{ }^{*} e s\right)$ bis His girlfriend a proposal to make dares Peter it until heute nicht. today not

b. Peter hat ( ${ }^{*}$ es) seiner Freundin einen Antrag zu machen bis Peter has it his girlfriend a proposal to make until heute nicht gewagt. today not dared 'Up until today, Peter didn't dare to propose to his girlfriend.'

In other words, extraposition and movement to Spec\&P yield a correlate es in their base position while A'-movement (58-a) does not. At first sight, it might be surprising why movement into the specifier of \&P in the ICC construction patterns with extraposition and not with A'-movement. However, it is remarkable that the two types of rightward movement pattern together as opposed to leftward A'-movement. Frey (2016), building on the theory of extraposition Frey (2015) and the theory Cyclic Linearization in Fox and Pesetsky (2005), offers an explanation for this pattern. The idea is that leftward movement of the complement clause without the correlate yields contradictory linearization statements: $e s>$ CLAUSE (in base position) and CLAUSE $>$ es (in final position). This does not happen with rightward movement. Thus Frey's account straightforwardly extends to the occurrence of correlate es in ICC constructions. 
I think the obligatory occurrence of the correlate in ICCs involving wagen 'dare' provides another nice argument for a movement account coupled with Frey's (2016) analysis of correlates.

\section{Conclusion}

In this paper, I have tried to present a coherent analysis of asymmetric coordination in German. The starting point of our discussion was what I called the Implicational Complement Coordination which exhibits all the hallmark properties of asymmetric coordination: Asymmetric variable binding, asymmetric scope of negation and high adverbs as well as asymmetric extraction. Interestingly, the construction freely alternates with an infinitival construction expressing the same meaning. Based on this observation, I proposed a derivational account in which the former, i. e. the coordinate construction is derived on the basis of the latter, i. e. the subordinate infinitival construction. The main assumption was that coordinate structures can under certain circumstances be derived via movement of an element into the specifier of the coordination phrase. This analysis allowed us to derive said properties of asymmetric coordination.

In the second part of this paper we tried to transfer the analysis to a more widespread asymmetric coordination construction in German: SLF-coordination. We saw that SLF-coordination basically exhibits the exact same properties as Implicational Complement Coordination, the only difference being that SLFcoordination does not freely alternate with a parallel infinitival construction. However, I have shown that we can assume that SLF-coordination, unlike the Implicational Complement Coordination, is created from an adjoined subordinate clause rather than from an argument clause. Once this assumption is made, the analysis can be transferred to cover SLF-coordination, a phenomenon that has created a lot of confusion over the last thirty-five years.

Acknowledgment: I would like to thank Gereon Müller, Fabian Heck, Doreen Georgi, Anke Himmelreich, Andrew Murphy, Katja Barnickel and two anonymous reviewers for their insights and constructive criticism.

\section{References}

Baker, Mark. 1988. Incorporation: A theory of grammatical function changing. Chicago, IL: University of Chicago Press. 
Barnickel, Katja. 2017. Deriving asymmetric coordination in German: A non-monotonic approach. Leipzig: Universität Leipzig dissertation.

Belletti, Adriana \& Luigi Rizzi. 1988. Psych-verbs and $\theta$-theory. Natural Language and Linguistic Theory 6(3). 291-352.

Bjorkman, Bronwyn. 2013a. A syntactic answer to a pragmatic puzzle: The case of asymmetric and. In Raffaella Folli, Christina Sevdali \& Robert Truswell (eds.), Syntax and its limits, vol. 2, 99-113. Oxford: Oxford University Press.

Bjorkman, Bronwyn. 2013b. A syntactic correlate of a semantic asymmetry. In Yelena Fainleib, Nicholas LaCara \& Yangsook Park (eds.), Proceedings of NELS 41, 391-408. Amherst, MA: GLSA.

Boeckx, Cedric, Norbert Hornstein \& Jairo Nunes. 2010. Control as movement. Cambridge: Cambridge University Press.

Büring, Daniel \& Katharina Hartmann. 1998. Asymmetrische Koordination. Linguistische Berichte 174. 172-201.

Castillo, Juan Carlos, John Drury \& Kleanthes Grohmann. 2009. Merge over move and the extended projection principle: MOM and the EPP revisited. Iberia: An International Journal of Theoretical Linguistics 1(1). 53-114.

Chen, Zongli \& Norbert Corver. 2013. Feature inheritance and the Comp-trace effect in Chinese relative clauses: The case of suo. Ms., University of Utrecht.

Chomsky, Noam. 1995. The minimalist program. Cambridge, MA: MIT Press.

Chomsky, Noam. 2000. Minimalist inquiries: The framework. In Roger Martin, David Michaels \& Juan Uriagereka (eds.), Step by step: Essays in minimalist syntax in honor of Howard Lasnik, 89-155. Cambridge, MA: MIT Press.

Chomsky, Noam. 2007. Approaching the UG from below. In Uli Sauerland \& Hans-Martin Gärtner (eds.), Interfaces + recursion = language? Chomsky's minimalism and the view from syntax-semantics, 1-29. Berlin \& New York: Mouton de Gruyter.

Chomsky, Noam. 2008. On phases. In Robert Freidin, Carlos Peregrin Otero \& Maria Luisa Zubizarreta (eds.), Foundational issues in linguistic theory. Essays in honor of Jean-Roger Vergnaud, 133-166. Cambridge, MA: MIT Press.

Chomsky, Noam. 2013. Problems of projection. Lingua 130. 33-49.

Collins, Chris. 2005. A smuggling approach to the passive in English. Syntax 8(2). 81-120.

Culicover, Peter W. \& Ray Jackendoff. 1997. Semantic subordination despite syntactic coordination. Linguistic Inquiry 28(2). 195-217.

Drummond, Alex. 2011. Binding phenomena within a reductionist theory of grammatical dependencies. College Park, MD: University of Maryland dissertation.

Fischer, Silke. 2016. On the locality of control and islands in German: Exploring a hybrid theory of control. Ms., University of Stuttgart.

Fortmann, Christian. 2005. Die Lücken im Bild der Subjektlückenkontruktion. Linguistische Berichte 204. 441-476.

Fox, Danny \& David Pesetsky. 2005. Cyclic linearization of syntactic structure. Theoretical Linguistics 31(1-2). 1-45.

Frampton, John \& Sam Gutmann. 1999. Cyclic computation: A computationally efficient minimalist syntax. Syntax 2(1). 1-27.

Frey, Werner. 2015. Zur Struktur des Nachfelds im Deutschen. In Hélène Vinckel-Roisin (ed.), Das Nachfeld im Deutschen: Theorie und Empirie, 53-75. Berlin \& Boston: de Gruyter.

Frey, Werner. 2016. On properties differentiating constructions with inner-sentential pro-forms for clauses. In Werner Frey, André Meinunger \& Kerstin Schwabe (eds.), Inner-sentential 
propositional proforms: Syntactic properties and interpretative effects, 1-21. Amsterdam: Benjamins.

Grewendorf, Günther. 1989. Ergativity in German. Dordrecht: Foris.

Hale, Ken \& Samuel Keyser. 1993. On argument structure and the lexical expression of syntactic relations. In Ken Hale \& Samuel Keyser (eds.), The view from building 20: Essays in honor of Sylvain Bromberger, 53-110. Cambridge, MA: MIT Press.

Heycock, Caroline \& Anthony Kroch. 1994. Verb movement and coordination in a dynamic theory of licensing. The Linguistic Review 11(3-4). 257-284.

Höhle, Tilman. 1983. Subjektlücken in Koordinationen. Ms., Universität Köln. [Published in Stefan Müller, Marga Reis \& Frank Richter (eds.), Beiträge zur deutschen Grammatik. Gesammelte Schriften von Tilman N. Höhle, 193-218. Berlin: Language Science Press, 2018. DOI: 10.5281/zenodo.1169669].

Höhle, Tilman. 1990. Assumptions about asymmetric coordination in German. In Juan Mascaró \& Marina Nespor (eds.), Grammar in progress: GLOW essays for Henk van Riemsdijk, 221-236. Dordrecht: Foris.

Höhle, Tilman. 1991. On reconstruction and coordination. In Hubert Haider \& Klaus Netter (eds.), Representation and derivation in the theory of grammar, 139-197. Dordrecht: Kluwer.

Holler, Anke. 2013. Reanalyzing German correlative es. In Stefan Müller (ed.), Proceedings of the 20th International Conference on Head-Driven Phrase Structure Grammar, 90-109. Stanford, CA: CSLI Publications.

Hornstein, Norbert. 1999. Movement and control. Linguistic Inquiry 30(1). 69-96.

Hornstein, Norbert. 2001. Move! A minimalist theory of construal. Malden, MA: Blackwell. Hornstein, Norbert. 2009. A theory of syntax. Cambridge: Cambridge University Press.

Jakobson, Roman. 1971. Selected writings, vol. 2: Word and language. The Hague: Mouton. Johannessen, Janne Bondi. 1998. Coordination. Oxford: Oxford University Press.

Johnson, Kyle. 2002. Restoring exotic coordinations to normalcy. Linguistic Inquiry 33(1). 97-156.

Kratzer, Angelika. 1996. Severing the external argument from its verb. In Johan Rooryck \& Laurie Zaring (eds.), Phrase structure and the lexicon, 109-137. Dordrecht: Kluwer.

Lakoff, George. 1986. Frame semantic control of the coordinate structure constraint. Proceedings from the Annual Meeting of the Chicago Linguistic Society 22(2). 152-167.

Landau, Idan. 2000. Elements of control: Structure and meaning in infinitival constructions. Dordrecht: Kluwer.

Landau, Idan. 2004. The scale of finiteness and the calculus of control. Natural Language and Linguistic Theory 22(4). 811-877.

Landau, Idan. 2008. Two routes of control: Evidence from case transmission in russian. Natural Language and Linguistic Theory 26(4). 877-924.

Landau, Idan. 2013. Control in Generative Grammar. Cambridge: Cambridge University Press.

Mohr, Sabine. 2005. V2, discourse functions and Split-CP. Paper presented at the Workshop "Sentence-initial and sentence-final position" as part of the Societas Linguistica Europeae 38 Conference, Valencia, September 9, 2005.

Munn, Alan Boag. 1987. Coordinate structure and X-bar theory. McGill Working Papers in Linguistics 4(1). 121-140.

Pitteroff, Marcel, Artemis Alexiadou, Jeannique Darby \& Silke Fischer. 2017. On partial control in German. Journal of Comparative Germanic Linguistics 20(2). 139-185. 
Ramchand, Gillian. 2008. Verb meaning and the lexicon: A first phase syntax. Cambridge: Cambridge University Press.

Reich, Ingo. 2007. From phases to ATB-movement. Proceedings from the Annual Meeting of the Chicago Linguistic Society 43(2). 217-232.

Reich, Ingo. 2008. From discourse to odd combinations - on asymmetric coordination and subject gaps in german. In Catherine Fabricius-Hansen \& Wiebke Ramm (eds.), 'Subordination' versus 'coordination' in sentence and text, 281-303. Amsterdam: Benjamins.

Reich, Ingo. 2009. Asymmetrische Koordination im Deutschen. Tübingen: Stauffenburg.

Reis, Marga. 1993. Satzfügung und kommunikative Gewichtung: Zur Grammatik und Pragmatik von Neben- vs. Unterordnung am Beispiel "implikativer” und-Konstruktionen im Deutschen. In Marga Reis (ed.), Wortstellung und Informationsstruktur, 203-249. Tübingen: Niemeyer.

Reis, Marga \& Angelika Wöllstein. 2010. Zur Grammatik (vor allem) konditionaler V1-Gefüge im Deutschen. Zeitschrift für Sprachwissenschaft 29(1). 111-179.

Repp, Sophie. 2009. Negation in gapping. Oxford: Oxford University Press.

Rizzi, Luigi. 1997. The fine structure of the left periphery. In Liliane Haegeman (ed.), Elements of grammar, 281-331. Dordrecht: Kluwer.

Rizzi, Luigi \& Ur Shlonsky. 2006. Satisfying the subject criterion by a non-subject: English locative inversion and heavy NP shift. In Mara Frascarelli (ed.), Phases of interpretation, 341-360. Berlin \& New York: Mouton de Gruyter.

Rizzi, Luigi \& Ur Shlonsky. 2007. Strategies of subject extraction. In Uli Sauerland \& Hans-Martin Gärtner (eds.), Interfaces + recursion = language? Chomsky's minimalism and the view from syntax-semantics, 115-160. Berlin \& New York: Mouton de Gruyter.

Ross, John Robert. 1967. Constraints on variables in syntax. Cambridge, MA: MIT dissertation. [Published as Infinite Syntax!. Norwood, N]: Ablex, 1986].

Salzmann, Martin. 2012. A derivational ellipsis approach to ATB-movement. The Linguistic Review 29(3). 397-438.

Salzmann, Martin. 2017. Displaced morphology in German. An argument for post-syntactic morphology. In Andrew Larmont \& Katerina Tetzloff (eds.), Proceedings of NELS 47, vol. 3, 77-90. Amherst, MA: GLSA.

Sigurðsson, Halldor. 2008. The case of PRO. Natural Language and Linguistic Theory 26(2). 403-450.

Sternefeld, Wolfgang. 2007. Anmerkungen zur sogenannten Subjektlückenkontruktion. Paper presented at the departmental colloquium series, Department of Linguistics, University of Leipzig, July 20, 2005.

Sudhoff, Stefan. 2003. Argumentsätze und es-Korrelate. Berlin: Wissenschaftlicher Verlag.

Sudhoff, Stefan. 2016. Correlates of object clauses in German and Dutch. In Werner Frey, Andre Meinunger \& Kerstin Schwabe (eds.), Inner-sentential propositional proforms: Syntactic properties and interpretative effects, 23-48. Amsterdam: Benjamins.

Truswell, Robert. 2010. Cyclic interpretation of event structure and A'-locality. In Raffaella Folli \& Christiane Ullbricht (eds.), Interfaces in linguistics: New research perspectives, 17-29. Oxford: Oxford University Press.

Weisser, Philipp. 2015a. Derived coordination - A minimalist perspective on clause chains, converbs and asymmetric coordination. Berlin \& Boston: de Gruyter.

Weisser, Philipp. 2015b. The syntactic side of conditional conjunction. Lingua 153. 42-65. 
Wunderlich, Dieter. 1988. Some problems of coordination in German. In Uwe Reyle \& Christian Rohrer (eds.), Natural language parsing and linguistic theories, 289-316. Dordrecht: Reidel.

Zhang, Niina. 2010. Coordination in syntax. Cambridge: Cambridge University Press.

Zoerner, Ed. 1995. Coordination: The syntax of \&P. Irvine, CA: University of California, Irvine dissertation. 